\title{
II-ReSEMblanCE NOMINALISM, CONJUNCTIONS AND TRUTHMAKERS
}

\author{
GONZALO RODRIGUEZ-PEREYRA
}

\begin{abstract}
The resemblance nominalist says that the truthmaker of 〈Socrates is white〉 ultimately involves only concrete particulars that resemble each other. Furthermore he also says that Socrates and Plato are the truthmakers of $\langle$ Socrates resembles Plato $\rangle$, and Socrates and Aristotle those of $\langle$ Socrates resembles Aristotle $\rangle$. But this, combined with a principle about the truthmakers of conjunctions, leads to the apparently implausible conclusion that 〈Socrates resembles Plato and Socrates resembles Aristotle〉 and 〈Socrates resembles Plato and Plato resembles Aristotle〉 have the same truthmakers, namely, Socrates, Plato and Aristotle. I shall argue that the resemblance nominalist can say that those conjunctions have the same truthmakers but these truthmakers make them true in different ways. I shall also use this view to account for the truthmakers of propositions like $\langle$ Socrates is white $\rangle$, and respond to previous objections by Cian Dorr and Jessica Wilson.
\end{abstract}

Resemblance nominalism is a theory according to which there are no universals and no tropes. What theories of universals and tropes explain by invoking universals and tropes, resemblance nominalism explains by invoking resembling particulars and sets, but sets, although abstract, are particular nevertheless. (Thus resemblance nominalism is nominalism in the traditional sense of the word, in that it rejects universals, not in the modern sense of the word, according to which nominalism entails the rejection of abstract objects.)

What does resemblance nominalism explain? Resemblance nominalism, and its competitor theories, trope theory and realism about universals, are solutions to the problem of universals. This problem is a problem about truthmakers, namely, to account for the truthmaker of propositions attributing a feature or characteristic to a par- 
ticular thing, propositions like 〈Socrates is white..$^{1}$ In a nutshell, the realist about universals says that the truthmakers for propositions like 〈Socrates is white〉 will involve a universal, the universal of whiteness. The trope theorist says that such a truthmaker will involve a trope, a white trope specifically. And the resemblance nominalist says that the truthmaker ultimately involves only concrete particulars, that is, particulars like Socrates and Plato, that resemble each other. Thus in my Resemblance Nominalism (RodriguezPereyra 2002) I defended a view according to which what makes 〈Socrates is white〉 true is the fact that Socrates is white, where this fact is the conjunctive fact whose conjuncts are resemblance facts between Socrates and each one of the white particulars, and where the constituents of any resemblance fact between Socrates and a white particular are Socrates and the white particulars in question. ${ }^{2}$ Thus, if we suppose that Socrates, Plato and Aristotle are the only white particulars, [Socrates is white] is [Socrates resembles Plato and Socrates resembles Aristotle]. ${ }^{3}$ But consider propositions (I) and (2):

\footnotetext{
${ }^{1}$ For reasons of space, I cannot defend here the claim that the problem of universals is a problem about truthmakers (for a defence of this claim see Rodriguez-Pereyra 2002, pp. 26-30). In this paper, as is now standard, I use angled brackets to designate propositions. And I shall use square brackets to designate facts. Thus ' $\langle P\rangle$ ' stands for the proposition that $P$ and ' $[P]$ ' stands for the fact that $P$.

${ }^{2}$ Thus facts are consistent with resemblance nominalism and therefore with nominalism, for complex facts have simpler facts as constituents, and simple facts have concrete particulars as their sole constituents (note also that no universals or tropes of resemblance are needed as constituents of resemblance facts). Thus facts need not be understood as they normally are, that is, as complex entities composed of particulars and universals. But note that even on this way of conceiving facts, facts obey a non-mereological mode of composition: thus although the only basic constituents of [Socrates resembles Plato and Socrates resembles Aristotle] are Socrates, Plato and Aristotle, this fact is not the sum Socrates + Plato + Aristotle. Some philosophers, David Lewis for instance, believe that the only mode of composition is mereological composition (Lewis I986, p. 92). But the doctrine that mereology is the only mode of composition is more a dogma than anything else. Indeed, many philosophers have argued that there is non-mereological composition (Armstrong I986, p. 85 ; Armstrong I997, p. II 8; Forrest 1986, p. 89).

${ }^{3}$ Strictly speaking, my view in Rodriguez-Pereyra (2002) was that, supposing that all and only white things are Socrates, Plato and Aristotle, [Socrates is white] is the conjunctive fact [Socrates resembles Socrates and Socrates resembles Plato and Socrates resembles Aristotle]. But I shall speak as if the view was that it is the fact [Socrates resembles Plato and Socrates resembles Aristotle]. This is because it simplifies exposition, and because I have started to toy with the idea that self-resemblance cannot be even part of what makes, say, a white particular white. But this change will not affect my discussion, in \$III, of Dorr's and Wilson's objections to the doctrines expressed in Rodriguez-Pereyra (2002)-these objections are independent of whether self-resemblance plays any role in what makes an $F$ thing $F$, and what I will say there about their objections will apply even if self-resemblance plays such a role and the fact [Socrates is white] is a fact like [Socrates resembles Socrates and Socrates resembles Plato and Socrates resembles Aristotle].
} 
(I) 〈Socrates resembles Plato and Socrates resembles Aristotle〉

(2) 〈Socrates resembles Plato and Plato resembles Aristotle〉

My view was that conjunctions were jointly or collectively made true by the truthmakers of the conjuncts (Rodriguez-Pereyra 2002, pp. 38-9). So what about the truthmakers of $(3),(4)$ and $(5)$ ?

(3) 〈Socrates resembles Plato〉

(4) $\langle$ Socrates resembles Aristotle $\rangle$

(5) 〈Plato resembles Aristotle $\rangle$

My answer in the book was that the truthmakers of true propositions asserting resemblance between two particulars are the resembling particulars themselves (Rodriguez-Pereyra 2002, p. II 5 ). ${ }^{4}$ Thus Socrates and Plato are the truthmakers of (3), Socrates and Aristotle are the truthmakers of (4), and Plato and Aristotle are the truthmakers of $(5) .^{5}$

As we shall see in \III, some critics thought that it follows from this that I am committed to giving propositions (6) and (7) the same truthmakers:

(6) 〈Socrates is white $\rangle$

(7) 〈Plato is white $\rangle$

I shall argue below that it does not follow from what I said in the book that (6) and (7) have the same truthmakers. But before doing that, I shall concentrate on a different but related question, the ques-

\footnotetext{
${ }^{4}$ Strictly speaking, this was not my answer, since in the book I took sentences to be truthbearers. But I now think that propositions are truthbearers, or at least the primary truthbearers. What I said in the book was that the truthmakers of sentences asserting resemblance between two particulars are the resembling particulars themselves. And I would have said the same of propositions asserting resemblance between two particulars had I taken propositions to be truthbearers.

${ }^{5}$ That Socrates and Plato are the truthmakers of $(3)$ might seem to go against truthmaker necessitarianism, the doctrine that truthmakers necessitate or entail the truths they make true-a doctrine I accept. But given the way the resemblance nominalist endorses the claim that Socrates and Plato are the truthmakers of $(3)$, and given the way he interprets truthmaker necessitarianism, there is no conflict between truthmaker necessitarianism and saying that Socrates and Plato are the truthmakers of $(3)$. For the resemblance nominalist takes particulars to be world-bound, that is, he takes particulars to exist in no more than one possible world. And the correct interpretation of truthmaker necessitarianism, given the ontology of modal realism to which the resemblance nominalist is committed, is that in every possible world in which the truthmakers exist, the proposition they make true is true. But then, since Socrates and Plato exist in only one world and in it they resemble each other, they necessitate (3). For discussion see Rodriguez-Pereyra (2002, pp. 34, 39-40, 99-I04, I I 7-I 8), Bird (2003) and Rodriguez-Pereyra (2003).
} 
tion about the truthmakers of (I) and (2). For it seems as if I am committed to the view that they have the same truthmakers, namely Socrates, Plato and Aristotle. And this seems to be implausible. Not because different propositions cannot have the same truthmakers, which is false, but because the role of Aristotle as truthmaker of these propositions seems intuitively to be different. Whatever the specific account one gives of what makes (I) and (2) true, it is reasonable to think that that Aristotle pairs up with Socrates to make (I) true, while he pairs up with Plato to make (2) true. Thus it would be better for resemblance nominalism if it could provide different accounts of what makes (I) true and what makes (2) true that respect this intuition about the different role of Aristotle (and consequently of Socrates and Plato) as a truthmaker for these propositions.

Thus in $\mathbb{S I I}$ I shall develop a philosophically interesting way in which the resemblance nominalist can tell different truthmaking stories about (I) and (2). More specifically, I shall develop a view according to which although (I) and (2) have the same truthmakers, these truthmakers make them true in different ways. In \$III I shall discuss Cian Dorr's and Jessica Wilson's objections to my account of the truthmakers of (6) and (7), and I shall then use the view developed in \$II to account for the truthmakers of (6) and (7).

\section{II}

There is at least one straightforward way of giving (I) and (2) different truthmakers. One can maintain, for instance, that the truthmakers of $(3),(4)$ and $(5)$ are the resemblance facts [Socrates resembles Plato], [Socrates resembles Aristotle] and [Plato resembles Aristotle], respectively. Then what makes (I) true are the facts [Socrates resembles Plato] and [Socrates resembles Aristotle], and what makes (2) true are the facts [Socrates resembles Plato] and [Plato resembles Aristotle]. This is a viable and interesting way of accounting for the truthmakers of $(\mathrm{I})-(5)$, but I am here interested in exploring a view according to which the truthmakers of (3), (4) and (5) are Socrates and Plato, Socrates and Aristotle, and Plato and Aristotle respectively, but in which these three particulars make (I) and (2) true in different ways.

How can different propositions have the same truthmakers but be made true by them in different ways? Consider propositions (8) and 
(9), and take them to be true:

(8) $\langle P \vee Q\rangle$

(9) $\langle P \wedge Q\rangle$

Suppose, for the sake of illustration, that propositions are made true by facts, and that there are such facts as $[P]$ and $[Q]$. If so, it would be standard to say that the disjunction is individually or separately made true by $[P]$ and by $[Q]$, while the conjunction is jointly made true by $[P]$ and $[Q] .^{6}$

Do these propositions have the same truthmakers? Yes, they do. Both are true in virtue of the facts $[P]$ and $[Q]$. For the fact that the conjunction has collective or joint truthmakers does not mean that it has an individual truthmaker of a rarefied kind. That the conjunction is jointly made true by $[P]$ and $[Q]$ does not mean that it bears the true in virtue of relation to some individual entity that somehow subsumes both $[P]$ and $[Q]$; it means that it bears the true in virtue of relation to $[P]$ and $[Q]$ collectively without bearing it to both of them individually. ${ }^{7}$

Thus (8) and (9) have the same truthmakers. For the things to which the disjunction is related by the truthmaking relation are the same as the things to which the conjunction is related by the truthmaking relation. But there is a difference in how those things are related by the truthmaking relation to those two propositions. The truthmaking relation relates $[P]$ and $[Q]$ individually to the disjunction, but it relates them collectively to the conjunction. That is why the disjunction is individually or separately made true by the facts $[P]$ and $[Q]$ but the conjunction is collectively made true by the facts $[P]$ and $[Q]$. This is simply a difference in how these facts enter the

\footnotetext{
${ }^{6}$ In this section I am trying to develop a resemblance nominalist way of accounting for what makes (I) and (2) true that does not invoke facts. But I shall introduce, explain and illustrate the position by using facts. This is simply because since I will use unstructured propositional variables in my examples of propositions, it simplifies exposition if I use fact variables in my examples of truthmakers. But I could have said, for instance, that while (8) is individually made true by Socrates and Plato, (9) is collectively made true by Socrates and Plato. The point I am trying to illustrate by means of facts is that it is standard to say that disjunctions are individually made true by the truthmakers of their disjuncts, and conjunctions are collectively made true by the truthmakers of their conjuncts (see, for example, Mulligan, Simons and Smith I984, pp. 3 I4-I 5). Every point I make using facts in this section can also be made without them.

${ }^{7}$ This would be true even if one treats ' $[P]$ and $[Q]$ ' as a plural term, for such a term, if it is genuinely plural and not a mere string of singular terms, does not stand for any singular object, but for the two things $[P]$ and $[Q]$. See, for instance, Oliver and Smiley $(2004$, p. 642).
} 
truthmaking relation, and so the fact that the conjunction has joint or collective truthmakers does not bring in any additional ontological commitments.

This difference in how $[P]$ and $[Q]$ make propositions (8) and (9) true is what I intend to capture by saying that (8) and (9) are made true by the same truthmakers in different ways. Thus two propositions can have the same truthmakers while being made true by them in different ways, i.e. individually or collectively.

Now, in the same way that the same entities can be related to some other entity individually or collectively, the same entities can be related to some other entity in different groups without all of them being collectively related to the entity in question and without each of them being individually related to the thing in question. For instance a tree might be surrounded by $a$ and $b$ on the one hand and by $c$ and $d$ on the other, without being surrounded by the four of them. This might happen if $a$ and $b$ surround it at one time, and $c$ and $d$ surround it at a different time. But it might also happen if $a$ and $b$, while surrounding the tree, are themselves surrounded by $c$ and $d$. And it might also happen if $c$ and $d$, while surrounding the tree, are standing on top of $a$ and $b$, which are also surrounding the tree in question. We might say that in these cases these things are related to the tree groupally without being related to it either collectively or individually. None of the things $a, b, c$ and $d$ individually surround the tree, nor do they do it collectively, yet they do it groupally: $a$ and $b$ on the one hand, and $c$ and $d$ on the other.

Consider (Iо) and assume that both disjuncts are true:

( Іо) $\langle\langle P \wedge Q\rangle \vee\langle R \wedge S\rangle\rangle$

If one thinks that the truthmakers of a disjunction are the truthmakers of its disjuncts separately and the truthmakers of a conjunction are the truthmakers of its conjuncts collectively, then (IO) is made true by the facts $[P]$ and $[Q]$ on the one hand and by the facts $[R]$ and $[S]$ on the other, but it is not made true collectively by the facts $[P],[Q],[R]$ and $[S]$. We might say that (Io) is made true groupally by $[P],[Q],[R]$ and $[S]$ : it is made true by $[P]$ and $[Q]$ on the one hand and it is made true by $[R]$ and $[S]$ on the other hand.

Something I would like to emphasize about these cases is that although a thing can be surrounded groupally by some things, or be made true groupally by some things, this does not mean that there are any things involved in the situation other than those things to 
which the thing is related groupally. In the case of disjunction (Io), saying that it is made true by the facts $[P]$ and $[Q]$ and also made true by the facts $[R]$ and $[S]$ is not saying that there is any entity over and above the facts $[P],[Q],[R]$ and $[S]$. In particular, by saying that certain things are groupally related to another I do not mean to reify any groups-whether or not groups are entities, the things themselves bear the relation in this case, not any groups formed by them.

Now there are two ways in which some things can be related groupally to another thing. It might be that the groups bear the relation to the relatum separately, or it might be that the groups bear the relation to the relatum collectively. The cases I have described so far are such that the entities that bear the relation groupally bear it separately groupally. That is, $a, b, c$ and $d$ are such that they surround the tree groupally because $a$ and $b$ surround it and $c$ and $d$ surround it, but the tree is surrounded by each group separately. In this case the tree bears the relation of being surrounded by to each group separately. ${ }^{8}$ The same is true in the case of disjunction (IO): the proposition bears the true in virtue of relation to the facts $[P]$ and $[Q]$ on the one hand and it bears it to the facts $[R]$ and $[S]$ on the other hand. The two groups of facts make the proposition true separately.

Now some things might bear some relations to other things collectively groupally. Consider (I I) and (I2), and assume, for the sake of the argument, not only that they are both true but that they are two distinct propositions:

$$
\begin{aligned}
& \text { ( I I) }\langle\langle P \wedge Q\rangle \wedge\langle R \wedge S\rangle\rangle \\
& \text { (I 2) }\langle P \wedge Q \wedge R \wedge S\rangle
\end{aligned}
$$

It is plausible to think that the distinction between (I I) and (I 2 ) is reflected at the level of truthmaking. In effect, it is plausible to think that although ( $\mathrm{I} 2$ ) is made true collectively by the facts $[P],[Q],[R]$ and $[S]$, this is not so in the case of (II). For (II) is made true by the facts $[P]$ and $[Q]$ on the one hand, together with the facts $[R]$ and $[S]$ on the other hand. Thus neither the facts $[P]$ and $[Q]$, nor the

\footnotetext{
${ }^{8}$ Although here, and occasionally elsewhere, I speak of the group as being one of the relata, this is just a manner of speaking to avoid cumbersome expression. What surrounds the tree is not a group of things, understood as an entity over and above the things that are supposed to be in the group, but these things themselves.
} 
facts $[R]$ and $[S]$ make (II) true separately: to make (II) true the two groups together are needed. In this case I shall say that (II) is made true by the facts $[P],[Q],[R]$ and $[S]$ collectively groupally.

That the facts $[P],[Q],[R]$, and $[S]$ make a certain proposition true collectively groupally does not impose any additional ontological commitments with respect to those of having $[P],[Q],[R]$ and $[S]$ making a certain proposition true collectively. That is, the ontology required to account for what makes proposition (II) true is the same as that required to account for what makes proposition (I2) true.

The same phenomenon of some things bearing a relation to another collectively groupally can be observed in relations other than truthmaking. Consider the relation of being surrounded twice by. It might be that our tree bears the relation of being surrounded twice by to $a, b, c$ and $d$-but not because any one of them individually surrounded it twice, nor because the four of them collectively surrounded it twice, but because $a$ and $b$ surrounded it at one time and $c$ and $d$ at another time, or because while surrouding it, $c$ and $d$ were standing on top of $a$ and $b$, or because, while surrounding it, $a$ and $b$ were surrounded by $c$ and $d$. In any of these cases the tree is surrounded twice by $a, b, c$ and $d$ collectively groupally.

Back to resemblance nominalism. According to the line of thought I am trying to develop here, to account for the truthmakers of (I) and (2) one does not need to postulate any entities other than Socrates, Plato and Aristotle. But this does not mean that each one of them individually makes those propositions true; nor does it mean that the three of them collectively make them true. What happens is that they make them collectively groupally true. That is, (I) is made true by Socrates and Plato together, together with Socrates and Aristotle together. And (2) is made true by Socrates and Plato together, together with Plato and Aristotle together.

This makes it possible to say that although the entities that make propositions (I) and (2) true are the same, they make them true in different ways. The entities that make them true are Socrates, Plato and Aristotle. But those propositions are made true by these entities grouped in different ways. (I) is made true by Socrates and Plato together, together with Socrates and Aristotle together, while (2) is made true by Socrates and Plato together, together with Plato and Aristotle together. The ontology is the same in both cases, but the way in which the entities enter the truthmaking relation is different. Thus there is a way in which resemblance nominalism can account 
for the truthmakers of propositions (I) and (2) without postulating facts, and invoking only resembling particulars. ${ }^{9}$

The truthmaking predicate is multigrade in its first place, since any number of things can make a proposition true. Thus any number of arguments can occupy the first place of '... make ... true'. These arguments can be either singular or plural, since sometimes some things collectively make a proposition true without individually making it true.

That some entities can collectively make a proposition true without individually making it true means that the truthmaking predicate is non-distributive-at least with respect to the arguments occupying its first place. A predicate $F$ is said to be distributive if, in virtue of the meaning of $F$, whenever some things are $F$, each one of them is $F$ (McKay 2006, p. 5). Thus '... make ... true' is non-distributive, since $[X]$ and $[Y]$ might be such that they make $\langle P\rangle$ true without either being such that it makes it true. The non-distributivity of a predicate need not be thought to bring in additional commitments. Thus the fact that Socrates and Plato collectively or jointly make $\langle$ Socrates resembles Plato $\rangle$ true brings no additional ontological commitments over and above those to Socrates and Plato.

Let me introduce a new feature of predicates. I define $F$ as an associative predicate if and only if, in virtue of the meaning of $F$, whenever some things are collectively groupally $F$, then they are collectively $F$. Thus if $F$ is an associative predicate then if some things $X$ and some things $Y$ are collectively $F$ then for any things $Z$, such that something is one of the $Z s$ if and only if it is one of the $X s$ or one of the $Y$ s, the $Z$ s are collectively $F$. '... move the piano' is an associative predicate. It is in virtue of the meaning of '... move the piano' that if $a$ and $b$, together with $c$ and $d$, move the piano, then $a, b, c$ and $d$ together move the piano.

What I have been arguing is that the truthmaking predicate is not

\footnotetext{
${ }^{9}$ This view does not invoke sets to account for what makes (I) and (2) true. But resemblance nominalism, as developed in Rodriguez-Pereyra (2002), is committed to sets-this is part of what makes it possible to solve the imperfect community difficulty. Is the appeal to pluralities involved in this way of accounting for what makes (I) and (2) true sufficient for the resemblance nominalist to reject sets? Probably not if the resemblance nominalist still adheres to the idea that resemblance is a dyadic relation. For unless one admits sets (pairs, specifically) as relata of the relevant resemblance relation, I do not see how one is going to solve the imperfect community difficulty and related problems. In $\$$ III I shall presuppose that resemblance nominalism needs sets (pairs) to solve the imperfect community difficulty. But whether this is so is worth exploring by those willing to continue developing resemblance nominalism.
} 
only non-distributive but also non-associative. The truthmaking predicate is non-vacuously non-associative since, for instance, Socrates and Plato (the Xs) and Socrates and Aristotle (the Ys) jointly or collectively make proposition (I) true, but Socrates, Plato and Aristotle (the $\mathrm{Zs}$ ) do not collectively make it true.

Truthmaking is not the only non-associative predicate. Another such predicate is '... form two circles'. Suppose $a, b, c$ and $d$ are all of semi-circular shape. Suppose that $a$ and $b$ are arranged so as to form a circle, and $c$ and $d$ are arranged so as to form another circle. Then $a$ and $b$, together with $c$ and $d$, form two circles. But it does not follow that $a, b, c$ and $d$ collectively form two circles, since they do not collectively form any circles at all.

That the truthmaking predicate is non-associative shows that the truthmaking predicate might sometimes be understood as taking a superplural argument in the first place. 'Socrates and Plato together with Socrates and Aristotle' is a superplural expression, since it is a plural expression-it refers to Socrates, Plato and Aristotle-that stands to the plural expressions 'Socrates and Plato' and 'Socrates and Aristotle' as these stand to the singular terms 'Socrates' and 'Plato' and 'Socrates' and 'Aristotle' respectively. Thus the truthmaking predicate can sometimes function as a superplural predicate (cf. Linnebo and Nicolas 2008, p. I93). ${ }^{10}$

I am not saying that the truthmaking predicate always takes superplural arguments. I am saying that it can take such arguments. But sometimes it takes plural arguments, for instance, when we say that Socrates and Plato make 〈Socrates resembles Plato〉 true, meaning that they make it true collectively. And sometimes it takes singular arguments, for instance, when we say that Socrates makes $\langle$ Socrates exists $\rangle$ true. ${ }^{11}$

\footnotetext{
${ }^{10}$ The considerations presented in this paper generalize, and should therefore support the view that the truthmaking predicate can take plural predicates of any order (possibly including infinite order), that is, not just superplural arguments, but also super-superplural arguments, and so on. It should also be noted that they also support the view that the truthmaking predicate takes plural predicates of 'mixed order'. For instance, what makes $\langle$ Aristotle exists and Socrates resembles Plato $\rangle$ true is Aristotle together with Socrates and Plato together. 'Aristotle together with Socrates and Plato together' (or 'Aristotle and (Socrates and Plato)') would be a superplural expression of 'mixed order', since it is obtained combining a singular and a first-order plural expression. I am indebted to Øystein Linnebo for alerting me to the points in this footnote.

${ }^{11}$ Some might be tempted to say that sometimes it takes, not a plural argument, but a plurality of singular arguments, as when we say that Socrates and Plato make 〈Someone exists true, meaning that they make it true separately or individually. I think this is right, but the
} 
Note that the line developed here rejects the thought that, in general, a conjunction is collectively made true by the truthmakers of its conjuncts. For sometimes a conjunction is made true collectively groupally by the truthmakers of its conjuncts. Thus it might be thought that this line of thought is not in the spirit of truthmaker theory, and that it is an ad hoc innovation made just to solve a difficulty. But if the possibility of many things collectively but not individually making true a proposition is in the spirit of truthmaker theory, then the possibility of many entities collectively groupally making true a proposition but not collectively making it true is a natural extension of the original idea. Furthermore, the fact that there are relations other than truthmaking that can be borne collectively groupally without being borne collectively should help to dispel the sense that there is any ad hoc move here.

\section{III}

In the previous section I proposed a resemblance nominalist view about what makes conjunctions (I) and (2) true. In this section I shall apply that view to (6) and (7). But before doing that, I shall discuss objections by Cian Dorr (2005) and Jessica Wilson (2006) to what I said about the truthmakers of (6) and (7) in Rodriguez-Pereyra (2002).

There I committed myself to the view that a proposition like $\langle a$ resembles $b, \ldots$, and $a$ resembles $z\rangle$ is made true by $a, b, \ldots$, and $z$, and I claimed that the facts [Socrates is white] and [Plato is white] are the facts [Socrates resembles Plato and Socrates resembles Aristotle] and [Plato resembles Socrates and Plato resembles

difference between the case in which it takes a plural argument and the case in which it takes a plurality of singular arguments is merely syntactic: it is the difference between taking a semantically plural syntactic unity and taking a plurality of semantically singular syntactic unities. The difference does not seem to be very significant, and none of the main points in the paper would be affected if it were the case that the truthmaking predicate took plural arguments but not pluralities of singular ones. It should also be noted that we can say that Socrates and Plato collectively make $\langle$ Socrates resembles Plato $\rangle$ true using the singular names 'Socrates' and 'Plato', and we can also say that Socrates and Plato individually make 〈Someone exists $\rangle$ true using the plural name 'Socrates and Plato'. In a similar vein, some might be tempted to think that the truthmaking predicate takes, not superplural arguments, but pluralities of plural arguments. Again, I think the difference is merely syntactic: it is the difference between taking a semantically superplural syntactic unity and taking a plurality of semantically plural syntactic unities. I think this difference is not significant for the points of this paper. 
Aristotle]. ${ }^{12}$ Dorr (2005) and Wilson (2006) objected that I violated the desideratum that propositions like $\langle a$ is $F\rangle$ and $\langle b$ is $F\rangle$, that is, propositions like (6) and (7), have different truthmakers. Here is what Wilson says:

[I]t is plausible that the truthmakers of some claims are jointly the truthmakers for the conjunctions of these claims. Hence if property attributions are conjunctions of resemblance claims, and the truthmakers of resemblance claims are just the resembling particulars, then the truthmakers for both ' $a$ is $F$ ' and ' $b$ is $F$ ' will be just $a, b, \ldots$, and $z$. Rodriguez-Pereyra's account thus faces the same difficulty as the (simpler) ostrich view he rejects. (Wilson 2006, p. 242)

\section{And this is what Dorr says:}

I found Rodriguez-Pereyra's treatment of truthmaking rather perplexing. On the one hand, he is happy to admit conjunctive facts and facts about resemblance. On the other hand, he maintains that conjunctions are jointly made true by the truthmakers of their conjuncts, and that truths about resemblance are jointly made true by the two resembling particulars. Given that the fact that $a$ is $F$ turns out on RodriguezPereyra's account to be a conjunctive fact, this seems to entail that the truth that $a$ is $F$ is jointly made true by all the $F$ particulars ...; exactly the same things jointly make it true that anything else is $F$. But whatever reason Rodriguez-Pereyra might have for holding that the truth that $a$ is $F$ must have different truthmakers from the truth that $a$ is $G$, one would think that there should be at least as much reason to hold that the truth that $a$ is $F$ must have different truthmakers from the truth that $b$ is $F$, when $a \neq b$. (Dorr 2005, pp. 460-I)

As I said, the point of both objections is that I have violated the desideratum that propositions like $\langle a$ is $F\rangle$ and $\langle b$ is $F\rangle$ have different truthmakers. But the two objections are subtly different. I think that Dorr represents my position in the book accurately, or more accurately than Wilson does, but he is mistaken that I have (or seem to have) violated the desideratum that what makes $\langle a$ is $F\rangle$ true is not

\footnotetext{
12 That facts like [Socrates is white] are conjunctive facts whose conjuncts are resemblance facts is asserted in Rodriguez-Pereyra (2002, pp. 86-7) (for more on what I said about facts, see note 3 above). Although I never explicitly affirmed that a proposition like $\langle a$ resembles $b, \ldots$, and $a$ resembles $z\rangle$ is made true by $a, b, \ldots$, and $z$, I was implicitly committed to it, since I maintained that resemblance propositions are made true by the two resembling particulars (p. I I 5) and that conjunctions are jointly (collectively) made true by the truthmakers of their conjuncts (pp. 38-9).
} 
what makes $\langle b$ is $F\rangle$ true. I think that Wilson misrepresents me, but if I had said what she takes me to have said, she would have been right.

The difference between the two objections will become clear later on. Consider Dorr's objection first. Given what he says in the passage above, he is attributing to me the idea that if $a, b, \ldots$, and $z$ are all the $F$ particulars, then $\langle a$ resembles $b, \ldots$, and $a$ resembles $z\rangle$ is made true by $a, b, \ldots$, and $z$. This attribution is correct, given what I said in my book. And he thinks that from these ideas plus the idea that $[a$ is $F]$ is a conjunctive fact whose conjuncts are resemblance facts, it follows (or seems to follow) that the truth $\langle a$ is $F\rangle$ is made true by $a, b, \ldots$, and $z$. But since $\langle b$ resembles $a, \ldots$, and $b$ resembles $z\rangle$ is also made true by $a, b, \ldots$, and $z$, these things also make $\langle b$ is $F\rangle$ true; therefore $\langle a$ is $F\rangle$ and $\langle b$ is $F\rangle$ have the same truthmakers. The following inference is essential to Dorr's argument:

(A) $[a$ is $F]=[a$ resembles $b, \ldots$, and $a$ resembles $z]$

(в) $\langle a$ resembles $b, \ldots$, and $a$ resembles $z\rangle$ is made true by $a, b$, $\ldots$, and $z$.

Therefore,

(C) $\langle a$ is $F\rangle$ is made true by $a, b, \ldots$, and $z$.

But (C) does not follow from (A) and (B), and therefore that $\langle a$ is $F\rangle$ and $\langle b$ is $F\rangle$ have the same truthmakers does not follow from (A) and (B). The reason why (C) does not follow from those premisses is that $\langle a$ is $F\rangle$ and $\langle a$ resembles $b, \ldots$, and $a$ resembles $z\rangle$ are different truths, and $[a$ is $F]$ is a conjunctive fact, not the totality of $F$ particulars. Thus Dorr has not shown that what I said in RodriguezPereyra (2002) violates the desideratum that what makes $\langle a$ is $F\rangle$ true is not what makes $\langle b$ is $F\rangle$ true.

But here is an argument whose conclusion is that $\langle a$ is $F\rangle$ is made true by $a, b, \ldots$, and $z$ :

(в) $\langle a$ resembles $b, \ldots$, and $a$ resembles $z\rangle$ is made true by $a, b$, $\ldots$, and $z$.

(D) $\langle a$ is $F\rangle$ is made true by [ $a$ resembles $b, \ldots$, and $a$ resembles $z]$. 
(E) If $x_{\mathrm{I}}, \ldots, x_{n}$ make $\langle P\rangle$ true, and $[P]$ makes $\langle Q\rangle$ true, then $x_{\mathrm{I}}, \ldots, x_{n}$ make $\langle Q\rangle$ true.

Therefore,

(C) $\langle a$ is $F\rangle$ is made true by $a, b, \ldots$, and $z$.

The mechanics of this argument are obvious. But the problem is that $(\mathrm{E})$ is false. For suppose that $\langle P \wedge Q\rangle$ is true in virtue of $[P]$ and $[Q]$ together, that is, $[P]$ and $[Q]$ jointly make $\langle P \wedge Q\rangle$ true. And suppose, furthermore, that there is a conjunctive fact $[P \wedge Q]$. Then $\langle$ There is a conjunctive fact $\rangle$ is made true by $[P \wedge Q]$. But $\langle$ There is a conjunctive fact $\rangle$ is not made true by $[P]$ and $[Q]$ together.

Wilson objects to my example. She says that it is implausible that $[P]$ and $[Q]$ jointly make $\langle P \wedge Q\rangle$ true but do not make $\langle$ There is a conjunctive fact $\rangle$ true. She adds, "Whatever makes "P $\wedge \mathrm{Q}$ " true also makes true "There is a conjunctive fact", just as whatever makes true a specific existential claim also makes true "Something exists", (Wilson 2006, p. 242 n.4). But what she finds implausible is, in fact, plausible. For since some facts together are not a conjunctive fact, given that some facts together are the truthmakers of a proposition like $\langle P \wedge Q\rangle$, it seems clear that the truthmakers of $\langle P \wedge Q\rangle$ need not be the truthmakers of $\langle$ There is a conjunctive fact $\rangle$. To make $\langle$ There is a conjunctive fact $\rangle$ true we need an extra conjunctive fact, over and above $[P]$ and $[Q]$ together. (And, by the way, ' $P \wedge Q$ ' is not related to 'There is a conjunctive fact' as specific existential claims are related to 'Something exists'. That is, ' $P \wedge Q$ ' is not an instance of 'There is a conjunctive fact'. An instance of it is, for example, ' $[P \wedge Q]$ is a conjunctive fact'.)

But note that even if (E) were true, all that would follow is that the white particulars would be truthmakers of both 〈Socrates is white $\rangle$ and $\langle$ Plato is white $\rangle$. This does not mean that these propositions have the same truthmakers, only that they share some, since [Socrates is white] would be a truthmaker of $\langle$ Socrates is white $\rangle$ but not of $\langle$ Plato is white $\rangle$, and [Plato is white] would be a truthmaker of $\langle$ Plato is white $\rangle$ but not of $\langle$ Socrates is white $\rangle$. The facts [Socrates is white] and [Plato is white] are conjunctive facts whose conjuncts are resemblance facts. But although the constituents of all the 'basic' resemblance facts whose conjunction forms [Socrates is white] are the same as the constituents of the 'basic' resemblance facts whose conjunction forms [Plato is white], the constituents of [Socrates is 
white] are not the same as the constituents of [Plato is white], for, to give just an example, [Socrates resembles Aristotle] is a constituent of [Socrates is white] but not of [Plato is white]. ${ }^{13}$

As I said, Wilson's objection is different from Dorr's. Wilson claims that if propositions attributing a property to a particular are conjunctive propositions whose conjuncts are resemblance propositions, then since the truthmakers of conjunctions are the truthmakers of their conjuncts, it follows that $\langle a$ is $F\rangle$ and $\langle b$ is $F\rangle$ have the same truthmakers, since both propositions are jointly made true by all the $F$ particulars. She is right that this is what follows from such

${ }^{13}$ Here are two other arguments whose conclusion is (c):

(A) $[a$ is $F]=[a$ resembles $b, \ldots$, and $a$ resembles $z]$

(B) $\langle a$ resembles $b, \ldots$, and $a$ resembles $z\rangle$ is made true by $a, b, \ldots$, and $z$.

(F) $\langle[P]$ exists $\rangle$ and $\langle P\rangle$ have the same truthmakers.

Therefore,

(C) $\langle a$ is $F\rangle$ is made true by $a, b, \ldots$, and $z$.

(B) and (F) entail that $\langle[a$ resembles $b, \ldots$, and $a$ resembles $z]$ exists $\rangle$ is made true by $a, b$, $\ldots$, and $z$. Given (A), $\langle[a$ is $F]$ exists $\rangle$ and $\langle[a$ resembles $b, \ldots$, and $a$ resembles $z]$ exists $\rangle$ have the same truthmakers, and so $\langle[a$ is $F]$ exists $\rangle$ is made true by $a, b, \ldots$, and $z$. By $(\mathrm{F})$, it follows (C), that $\langle a$ is $F\rangle$ is made true by $a, b, \ldots$, and $z$.

But I can see no reason to accept $(\mathrm{F})$. Suppose both $\langle[P \wedge Q]$ exists $\rangle$ and $\langle P \wedge Q\rangle$ are true. It is not implausible to maintain that while the latter is made true separately by $[P \wedge Q]$ on the one hand and by $[P]$ and $[Q]$ together on the other, the former is made true only by $[P \wedge Q]$, for it is not implausible to maintain that the only truthmaker of a proposition asserting existence of an entity is the entity whose existence it asserts. Even if the existence of $[P \wedge Q]$ entails that of $[P]$ and $[Q]$, the latter are not the truthmakers of $\langle[P \wedge Q$ exists] $\rangle$, in the same way in which my parts are not the truthmakers of $\langle$ I exist $\rangle$.

This is the second argument:

(A) $[a$ is $F]=[a$ resembles $b, \ldots$, and $a$ resembles $z]$

(G) Nothing but $a, b, \ldots, z$ makes $\langle a$ resembles $b, \ldots$, and $a$ resembles $z\rangle$ true.

(H) For every $\langle P\rangle$ with a truthmaker, if $[P]$ exists, then $[P]$ makes $\langle P\rangle$ true.

Therefore,

(C) $\langle a$ is $F\rangle$ is made true by $a, b, \ldots$, and $z$.

The argument would be that, by $(\mathrm{H}),[a$ resembles $b, \ldots$, and $a$ resembles $z]$ makes $\langle a$ resembles $b, \ldots$, and $a$ resembles $z\rangle$ true. But then, by $(\mathrm{G}),[a$ resembles $b, \ldots$, and $a$ resembles $z$ ] is the totality of $a, b, \ldots$, and $z$, and hence, by (A), the totality of $a, b, \ldots$, and $z$ is $[a$ is $F]$. By $(\mathrm{H}),[a$ is $F]$ makes $\langle a$ is $F\rangle$ true and so $a, b, \ldots$, and $z$ make $\langle a$ is $F\rangle$ true.

But I see no reason to accept $(\mathrm{G})$. Many propositions have more than one independent truthmaker. Disjunctions are one case, but they need not be the only case. As I have just said, if $[P \wedge Q]$ exists, it is not implausible that $\langle P \wedge Q\rangle$ is separately made true by $[P \wedge Q]$ on the one hand, and by $[P]$ and $[Q]$ together on the other hand. And $(\mathrm{H})$ is not sacrosanct either. Some people maintain that there are truths that have no truthmakers (Milne 2005, Simons 2005). Why couldn't one maintain that there are facts that do not make true anything? Such a position would even be consistent with truthmaker maximalism, which claims that every truth has a truthmaker. I am not saying that $(\mathrm{H})$ is false. I am saying that it is not evident, and there might be reasons to reject it; but in any case I am prepared to reject $(\mathrm{G})$. 
a supposition. But I never claimed that propositions like $\langle a$ is $F\rangle$ are in fact conjunctive propositions whose conjuncts are resemblance propositions. So her criticism does not apply to me. Thus Wilson has not shown that what I said in Rodriguez-Pereyra (2002) violates the desideratum that what makes $\langle a$ is $F\rangle$ true is not what makes $\langle b$ is $F\rangle$ true.

But although the theory presented and developed in RodriguezPereyra (2002) did not violate the desideratum that what makes $\langle a$ is $F\rangle$ true is not what makes $\langle b$ is $F\rangle$ true, it accounted for their truthmakers in terms of conjunctive facts whose conjuncts are resemblance facts. The theory developed in the previous section seems to allow the resemblance nominalist to account for what makes propositions like $\langle a$ is $F\rangle$ true without appealing to facts, and so, in a sense, simplifies the theory. For it seems that the resemblance nominalist can say that what makes $\langle a$ is $F\rangle$ true is what makes $\langle a$ resembles $b, \ldots$, and $a$ resembles $z\rangle$ true, where $a, b, \ldots$, and $z$ are all the $F$ particulars. And so what makes (6) and (7) true is what makes (I) and (2) true. And although (I) and (2) have the same truthmakers, this is not objectionable, since it is not the case that what accounts for the truth of (I) is what accounts for the truth of (2): they have the same truthmakers, but they are made true by them in different ways. Thus (6) and (7) have the same truthmakers, but they are made true by them in different ways.

But there is a simplification in what I have just said. The truthmakers of (6) and (7) cannot be the truthmakers of (I) and (2). This is because that Socrates, Plato, and Aristotle are the three white particulars is something more than merely the fact that they pairwise resemble each other, since they could pairwise resemble each other without thereby sharing any characteristic. In that case they would form an imperfect community. As I argued in Resemblance Nominalism, what makes them form a perfect community, that is, a class of things all of which share a certain characteristic, is that not only do they resemble each other, but their pairs resemble each other as well (Rodriguez-Pereyra 2002, pp. I 62-72). That is, what makes Socrates, Plato and Aristotle form a perfect community is that they resemble each other pairwise and so do \{Socrates, Plato\}, \{Socrates, Aristotle\} and \{Plato, Aristotle\}. So what makes (6) true is Socrates and Plato together, together with Socrates and Aristotle together, together with \{Socrates, Plato $\}$ and \{Socrates, Aristotle\} together, together with $\{$ Socrates, Plato $\}$ and $\{$ Plato, Aristotle\} together, together 
with \{Socrates, Aristotle\} and $\left\{\right.$ Plato, Aristotle\} together. ${ }^{14}$ But (7) is made true by Socrates and Plato together, together with Plato and Aristotle together, together with \{Socrates, Plato\} and \{Socrates, Aristotle\} together, together with \{Socrates, Plato\} and \{Plato, Aristotle\} together, together with \{Socrates, Aristotle\} and \{Plato, Aristotle\} together. ${ }^{15}$ So (6) and (7), on this view, have the same truthmakers, but they collectively groupally make (6) true in one way and collectively groupally make (7) true in another way. This means that what accounts for the truth of (6) and (7) is not the same.

To conclude, resemblance nominalism can give different accounts of the truth of (I) and (2) without using facts of resemblance. This requires taking those two propositions to have the same truth-makers, but to be made true by them in different ways. That is, Socrates, Plato and Aristotle are the truthmakers of both (I) and (2), but they collectively groupally make (I) true in one way, and collectively groupally make (2) true in another way. And, as we saw in the last section, the resemblance nominalist can also give different accounts of the truth of (6) and (7) without using facts of resemblance. In this case, the truthmakers are in both cases Socrates, Plato, Aristotle, \{Socrates, Plato\}, \{Socrates, Aristotle\}, and \{Plato, Aristotle\}. But they collectively groupally make (6) true in one way, and collectively groupally make (7) true in another way. ${ }^{16}$

\section{Oriel College \\ University of Oxford Oxford OXI 4EW}

\footnotetext{
${ }^{14}$ Assuming, of course, the fiction that Socrates, Plato and Aristotle are the only three white particulars.

${ }^{15}$ Thus although in Resemblance Nominalism I did not take the fact that Socrates is white to be the conjunctive fact [Socrates resembles Plato and Socrates resembles Aristotle and $\{$ Socrates, Plato\} resembles \{Socrates, Aristotle\} and \{Socrates, Plato $\}$ resembles $\{$ Plato, Aristotle\} and \{Socrates, Aristotle\} resembles \{Plato, Aristotle\}], the elements and reasons to do so were present in the book.

${ }^{16}$ I am grateful to audiences in Buenos Aires, Curitiba, Edinburgh, Geneva, Lima, Oxford, Padova, Paris, Rio de Janeiro, Sao Paulo, Villa Giardino, and at the Aristotelian Society in London for helpful comments on previous versions of this paper.
} 


\section{REFERENCES}

Armstrong, D. M. 1986: 'In Defence of Structural Universals'. Australasian Journal of Philosophy, 64, pp. 85-8.

- I997: A World of States of Affairs. Cambridge: Cambridge University Press.

Bird, Alexander 2003: 'Resemblance Nominalism and Counterparts'. Analysis, 63(3), pp. $22 \mathrm{I}-8$.

Dorr, Cian 2005: Review of Resemblance Nominalism: A Solution to the Problem of Universals. Mind, I I4, pp. 457-6I.

Forrest, Peter 1986: 'Neither Magic nor Mereology: A Reply to Lewis'. Australasian Journal of Philosophy, 64, pp. 89-9I.

Lewis, David I986: 'A Comment on Armstrong and Forrest'. Australasian Journal of Philosophy, 64, pp. 92-3.

Linnebo, Øystein, and David Nicolas 2008: 'Superplurals in English'. Analysis, 68(3), pp. 186-96.

McKay, Thomas J. 2006: Plural Predication. Oxford: Oxford University Press.

Milne, Peter 2005: 'Not Every Truth Has a Truthmaker'. Analysis, 65(3), pp. $22 \mathrm{I}-4$.

Mulligan, Kevin, Peter Simons, and Barry Smith I984: 'Truth-Makers'. Philosophy and Phenomenological Research, 44, pp. 287-32I.

Oliver, Alex, and Timothy Smiley 2004: 'Multigrade Predicates'. Mind, II3, pp. 609-8I.

Rodriguez-Pereyra, Gonzalo 2002: Resemblance Nominalism: A Solution to the Problem of Universals. Oxford: Oxford University Press.

2003: 'Resemblance Nominalism and Counterparts: Reply to Bird'. Analysis, 63 (3), pp. 229-37.

Simons, Peter 2005: 'Negatives, Numbers, and Necessity: Some Worries about Armstrong's Version of Truthmaking'. Australasian Journal of Philosophy, 82, pp. 253-6I.

Wilson, Jessica 2006: Review of Resemblance Nominalism: A Solution to the Problem of Universals. Philosophy and Phenomenological Research, $72(\mathrm{I})$, pp. $24 \mathrm{I}-6$. 